\title{
Entre as experiências de um estágio e a formação docente
}

\section{Between internship experiences and teacher's formation}

Entre las experiencias de una práctica supervisada y la formación docente

Roberto Barbosa Costa Filho ${ }^{1}$

\section{RESUMO}

Neste relato, reflito sobre as experiências vivenciadas durante a realização do primeiro estágio supervisionado do curso de Licenciatura em Letras: Língua Portuguesa. Esse estágio foi realizado um uma turma do $9^{\circ}$ ano de uma escola estadual de Campina Grande - PB. Fundamentando-me em reflexões do campo aplicado dos estudos da linguagem e da educação, muito mais que descrever as atividades realizadas, reflito sobre o ser professor nas particularidades situadas de uma escola pública. Dessa maneira, exponho as delícias e os dessabores que compuseram essa experiência para, quem sabe, subsidiar pautas sobre reformulações de currículos a fim de que a formação inicial seja mais condizente com os desafios atuais do ser professor.

Palavras-chave: Estágio; Formação docente; Língua Portuguesa.

\begin{abstract}
In this report, I reflect on the experiences lived during the first supervised internship of the Graduation in Letters: Portuguese Language. This internship was carried out in a 9th grade class at a state school in Campina Grande - PB. Based on reflections of the applied field of language studies and education, much more than describing the activities carried out, I reflect on being a teacher in the particularities of a public school. In this way, I expose the delights and the unpleasantness that made up this experience to, who knows, subsidize guidelines on reformulations of curricula so that the initial training is more consistent with the current challenges of being a teacher.
\end{abstract}

Keywords: Internship; Teacher's formation; Portuguese Language.

\section{RESUMEN}

En este informe, reflexiono sobre las experiencias vividas durante la primera práctica supervisada del Licencia en Letras: Lengua Portuguesa. Esta práctica supervisada se llevó a cabo en una clase de noveno grado en una escuela estatal en Campina Grande - PB. Basado en reflexiones del campo aplicado de los estudios de lenguaje y la educación, mucho más que describir las actividades realizadas, reflexiono sobre ser un maestro en las particularidades de una escuela pública. De esta manera, expongo las delicias y las molestias que conformaron

\footnotetext{
${ }^{1}$ UFCG - Universidade Federal de Campina Grande, Campina Grande/PB - Brasil.
} 
esta experiencia para, quién sabe, subsidiar las pautas sobre la reformulación de los planes de estudio para que la capacitación inicial sea más consistente con los desafíos actuales de ser maestro.

Palavras-chave: Práctica supervisada; Formación docente; Lengua Portuguesa.

\section{INTRODUÇÃO}

Considerando as discussões iniciadas em Costa Filho e Bazarim (2018; 2019), neste relato, recupero experiências vivenciadas em meu primeiro estágio supervisionado durante o curso de Licenciatura em Letras: Língua Portuguesa na Universidade Federal de Campina Grande (UFCG). Passado algum tempo, após a realização de outros estágios e a participação em alguns programas de iniciação à docência - Programa Institucional de Iniciação à Docência (PIBID) e Programa de Residência Pedagógica (RP) - retomar as memórias da primeira experiência em que assumi uma sala de aula, mesmo que na figura de professor-estagiário, ganha importante aspecto reflexivo na minha formação.

Tenho pensado, a partir dessas experiências e dos constructos epistemológicos construídos em meio às diversas leituras formativas realizadas (PIMENTA; LIMA, 2006; LIMA, 2008, apenas para citar algumas), que os cursos de licenciatura têm o desafio de articular três eixos necessários para a ação docente: a teoria aprendida sobre os seus objetos de ensino, os conhecimentos sobre a prática e a própria prática docente (COSTA FILHO; BAZARIM, 2018). Essa articulação, ou ao menos a reflexão sobre ela, ganha importante destaque durante os estágios, já que são espaços privilegiados para a construção da identidade profissional dos graduandos, em meio com a convivência e com a prática de ações de sua futura profissão.

Acrescento aqui que essas reflexões, certamente, não têm tomado somente a agenda dos graduandos, mas também dos docentes, especialmente daqueles que atuam como orientadores e/ou supervisores de estágio. Esses docentes durante a realização dos estágios assumem a missão de realocarem suas posições de formadores de professores e atualizarem suas visões sobre a escola, sobre o processo de ensino-aprendizagem, sobre os conhecimentos teóricos e práticos, sobre as demandas docentes, enfim, sobre infinitas questões que poderiam ser aqui colocadas. Ao passo que, em tese, façam parte da agenda desses docentes, as experiências de estágio também deveriam ter papel fundamental nas reformulações de currículos, materializados nos Projetos Pedagógicos de Cursos, a fim de possibilitar a (re)construção de uma formação condizente com os desafios atuais do ser professor.

Este relato, portanto, muito mais que descrever o desenvolvimento de meu primeiro estágio, visa se constituir como um espaço para reflexão do ser professor nas particularidades situadas de uma escola pública do munícipio de Campina Grande, estado da Paraíba. Por esta razão, além da introdução, organizo o texto em outras quatro seções nas quais exponho as delícias e dos dessabores dessa vivência: na seção seguinte, trato sobre os desafios do estágio para o graduando, especialmente o contato com a escola; logo após, descrevo sobre o planejamento de minha ação docente; posteriormente, reflito sobre os significados dessa prática para minha formação; por fim, apresento algumas considerações. 


\section{OS DESAFIOS DO ESTÁGIO E O CONTATO COM A ESCOLA}

Quando adentramos no estudo aprofundado da aprendizagem com as mais diversas manifestações $O$ trabalho de planejamento, negociação com as escolas recebedoras, desenvolvimento e avaliação de atividades, concentrados no período letivo de um semestre, muitas vezes dificulta a visão do todo. Dessa forma, pode ficar despercebida uma questão fundamental, que está na base de muitos dos nossos descontentamentos e conflitos no decorrer do Estágio que é o movimento de aproximação de duas instituições de ensino, cada uma trazendo valores, objetivos imediatos, cultura e relações de poder diferentes, com o objetivo de realizarem um trabalho comum: a formação de professores. No meio destes dois campos de força está o estagiário, preocupado em cumprir os requisitos acadêmicos propostos pelo professor - orientador da disciplina e transitar de maneira satisfatória pela escola na busca de aprendizagens sobre a profissão (LIMA, 2008, p. 198).

As palavras de Lima (2008), acima citadas, resumem de maneira bastante explícita os grandes problemas enfrentados pelos graduandos em licenciaturas para realização de estágio. As diferenças de objetivos e valores entre universidade e escola muitas vezes dificultam a entrada de estagiários no campo docente e os colocam em uma situação em que precisam lidar (com), resolver (os) e refletir (sobre) diversos fatores a fim de cumprir tal componente curricular. No curso de Licenciatura em Letras: Língua Portuguesa da Unidade Acadêmica de Letras (UAL) da UFCG, o graduando vivencia quatro estágios (Estágio de Língua Portuguesa: Ensino Fundamental; Estágio de Literatura: Ensino Fundamental; Estágio de Língua Portuguesa: Ensino Médio; Estágio de Literatura: Ensino Médio), correspondendo a 420 horas (equivalente a 28 créditos). Esses estágios são iniciados no $5^{\circ}$ período, com o estágio de Língua Portuguesa no Ensino Fundamental II (120 horas; 08 créditos) - alvo desse relato.

Tudo se inicia com o aceite da escola e do professor da Educação Básica para receber o estagiário em sua sala de aula. Neste ponto, necessariamente, não tive grandes problemas. Já conhecia a professora por causa de observações da prática docente em outros componentes curriculares do curso. Entretanto, acabei encontrando entraves para o começo das atividades, ora proveniente de questões pessoais dos envolvidos ora por repentinas mudanças de horário da instituição de ensino.

A escola em questão, pertencente à rede pública estadual da Paraíba e localizada no município de Campina Grande, passava por uma transição para o Programa de Educação Integral (Medida Provisória no 267 de 07 de fevereiro de 2018), tornando-se Escola Cidadã Integral. O objetivo primordial do programa era "planejar e executar um conjunto de ações inovadoras em conteúdo, método e gestão, direcionadas à melhoria da oferta e qualidade do ensino" (PARAÍBA, 2018, p. 1).

Em virtude da adaptação ao regime integral e à (re)constituição da equipe administrativa e pedagógica da escola, foram necessárias algumas mudanças de horário (pelo menos 4 mudanças desde o primeiro contato com a professora supervisora) que coincidiram com a realização deste estágio. A adaptação dos alunos da turma e a minha, em concomitância com as outras atividades e disciplinas universitárias, ao período integral também podem, e devem, ser vistas como obstáculos enfrentados.

De todo modo, consegui me adaptar e transcorrer com o estágio em uma turma de $9^{\circ}$ ano do Ensino Fundamental. A turma era constituída por 41 alunos, número possivelmente ocasionado pela diminuição na oferta de turmas depois da adesão da escola ao Programa Educação Integral. Esse número elevado de alunos por turma não é exclusividade dessa escola; é uma realidade cada vez 
mais recorrente no cotidiano de diversos professores espalhados pelo país. Muitas vezes, como no nosso caso, a estrutura da sala de aula sequer permite um número tão grande de pessoas, quase não sobrando espaço entre as carteiras para que o professor caminhe pelo espaço. Vale ressaltar que esse é apenas um dos problemas estruturais enfrentados em alguns casos.

Não coloco o número elevado de alunos e os problemas estruturais de algumas escolas para desmotivação na formação docente. Coloco-os enquanto realidades existentes e desafiadoras que não devem ser esquecidas ou negligenciadas já que interferem, em menor ou maior grau, no trabalho do professor. Por isso, cabem aos cursos de licenciatura, de algum modo, se preocuparem com isso e à sociedade em geral cobrar dos poderes governamentais melhores condições humanas e estruturais para as escolas públicas. A luta é constante e não deve ser, jamais, esquecida.

Dados os fatos durante a negociação com a escola e conhecimento da turma, passo ao planejamento da ação docente, o qual, diante das mudanças de horário, foi (re)planejado várias vezes.

\section{O MOMENTO DE PLANEJAR A AÇÃo DOCENTE}

Enquanto ação mediada por uma preparação prévia, parto de concepções provenientes do meu processo de formação, de modo amplo, e de orientação, de modo específico. Nessa direção, utilizo as contribuições sobre planejamento e avaliação elaboradas por Luckesi (2011a; 2011b) e Menegolla e Sant'Anna (2014), sobre sequência didática por Costa-Hübes e Simioni (2014), sobre o gênero textual crônica por Sá (1987) e Candido (1992), sobre elementos da narrativa por Abdala Junior (1995), Gancho (2002) e Junior (2009), sobre leitura e estratégias de compreensão por Koch e Elias (2006) e Rojo (2009) e sobre análise linguística por Costa-Hübes (2010).

Por planejamento, compreendo a atividade intencional com meios estabelecidos para atingir determinados fins projetados, sendo uma decisão a ser elaborada em conjunto (LUCKESI, 2011b). Ao tratar de um processo de ensino-aprendizagem em específico, é preciso ampliar a compreensão para visão de processo evolutivo, acompanhando uma ação progressiva e dinâmica para a aprendizagem dos alunos (MENEGOLLA; SANT'ANNA, 2014).

Visto dessa forma, o planejamento prescinde alguns instrumentos que sistematicamente proporcionem meios satisfatórios para a ação. Nesse sentido, Menegolla e Sant'Anna (2014) indicam uma ordem de ações necessárias à elaboração de um plano de ensino, a saber: sondagem da realidade, definição de objetivos, delimitação de conteúdos, escolha de procedimentos de ensino, seleção de recursos humanos e materiais, estabelecimento de um processo de avaliação. Essas ações, realizadas de forma consciente, têm muito a contribuir para a prática docente, atentando também aos intemperes cotidianos, e por isso me serviram de aparato para o meu planejamento de aulas.

Por avaliação, considero, conforme Luckesi (2011a), que sua perspectiva reside na construção do futuro, tendo por foco o que é realizado no presente. Nesse sentido, a avaliação busca ultrapassar os problemas diagnosticados enquanto processo de construção da aprendizagem e, por consequência, dos melhores resultados possíveis para a ação pedagógica. Assim, a avaliação deve ocorrer dialogicamente, com constante negociação entre os alunos e o professor.

Expostas essas considerações e como já anunciado em Costa Filho e Bazarim (2018), a preparação para o meu primeiro estágio ocorreu já a partir do componente Planejamento e avaliação, cursado 
um período antes ao da prática supervisionada. Nesse componente, elaborei e apliquei uma atividade diagnóstica, em concordância com a concepção de sondagem de Menegolla e Sant'Anna (2014) e de avaliação de Luckesi (2011a), para observar a competência leitora de uma turma da educação básica. Após a correção, houve a tabulação, a apresentação e a reflexão dos resultados atingidos pelos alunos. Só depois disso, foi elaborado um plano de ensino e uma sequência didática focalizando as principais dificuldades detectadas.

Tanto para essa atividade diagnóstica quanto para o plano de ensino e a sequência didática, selecionei o gênero textual crônica narrativa. Reportando à origem do gênero, em que o suporte de circulação eram os jornais impressos, Jorge de Sá (1987) destaca que o número restrito de laudas para a escrita da crônica fazia com que o redator tivesse que "explorar da maneira mais econômica possível o pequeno espaço de que dispõe" (SÁ, 1987, p. 8), sendo daí "que nasce sua riqueza estrutural" (SÁ, 1987, p. 8). Na simplicidade e na pretensão de não durar muito, este gênero textual consegue tornarse íntimo em relação à vida, de modo a deixar de lado qualquer seriedade nos problemas. Com isso, se propõe a ser um texto curto, leve e que, geralmente, aborda temas do cotidiano. Nas palavras de Antônio Cândido, a crônica é "amiga da verdade e da poesia nas suas formas mais diretas e também nas suas formas mais fantásticas" (CANDIDO, 1992, p. 14).

Retomando a atividade, apliquei-a na mesma escola na qual realizei o estágio em uma turma do $8^{\circ}$ ano, no fim de 2017, quando a escola ainda não era Cidadã Integral. Logo em seguida, busquei refletir sobre as respostas colhidas, devidamente tabuladas e apresentadas no interior do supracitado componente curricular, observando especialmente as dificuldades encontradas para a resolução das questões. Elaborei, com isso, um plano de ensino e uma sequência didática, que foram (re)visados e aplicados na realização do estágio supervisionado, considerando a permanência de parte da turma no $9^{\circ}$ ano, no ano seguinte (2018), e após realização de nova atividade diagnóstica para observação e implementação de outros pontos.

O plano, já com as alterações sofridas a partir dos resultados da aplicação de uma nova atividade diagnóstica, teve por objetivo geral ampliar a competência leitora dos alunos a partir do gênero textual crônica e como objetivos específicos: (re)conhecer o gênero textual crônica a partir da identificação de suas principais características; desenvolver as estratégias de leitura (formulação de hipóteses, conhecimento de mundo, localização de informações explícitas e implícitas, comparação de informações, inferências) para o gênero; identificar os elementos da narrativa no gênero; analisar os efeitos de sentido do adjetivo como caracterizador de personagens e espaços da crônica.

A sequência didática seguiu o modelo proposto por Swiderski e Costa-Hübes (2009² apud COSTAHÜBES; SIMIONI, 2014), adaptando o modelo proposto pelo grupo de estudos genebrino (DOLZ; NOVERRAZ; SCHNEUWLY, 2004) para a realidade brasileira. A sequência didática, que se propõe à apropriação de um gênero textual pelo aluno é adaptada pelas autoras considerando a necessidade de articulação entre os eixos de uso (oralidade, leitura e escrita) e de reflexão sobre a língua (análise linguística). Essa adaptação resultou no esquema a seguir, que foi utilizado para meu planejamento,

\footnotetext{
2 SWIDERSKI, R. M. S.; COSTA-HÜBES, T. C. Abordagem sociointeracionista \& sequência didática: relato de uma experiência. Línguas \& Letras, v. 10, n. 18, $1^{0}$ sem. 2009, p. 113-128. DOI: http://dx.doi.org/10.5935/rl\&l.v10i18.2253.
} 
especialmente o módulo de reconhecimento do gênero para cumprimento dos objetivos do plano de ensino.

Figura 1 - Esquema da sequência didática adaptada por Costa-Hübes

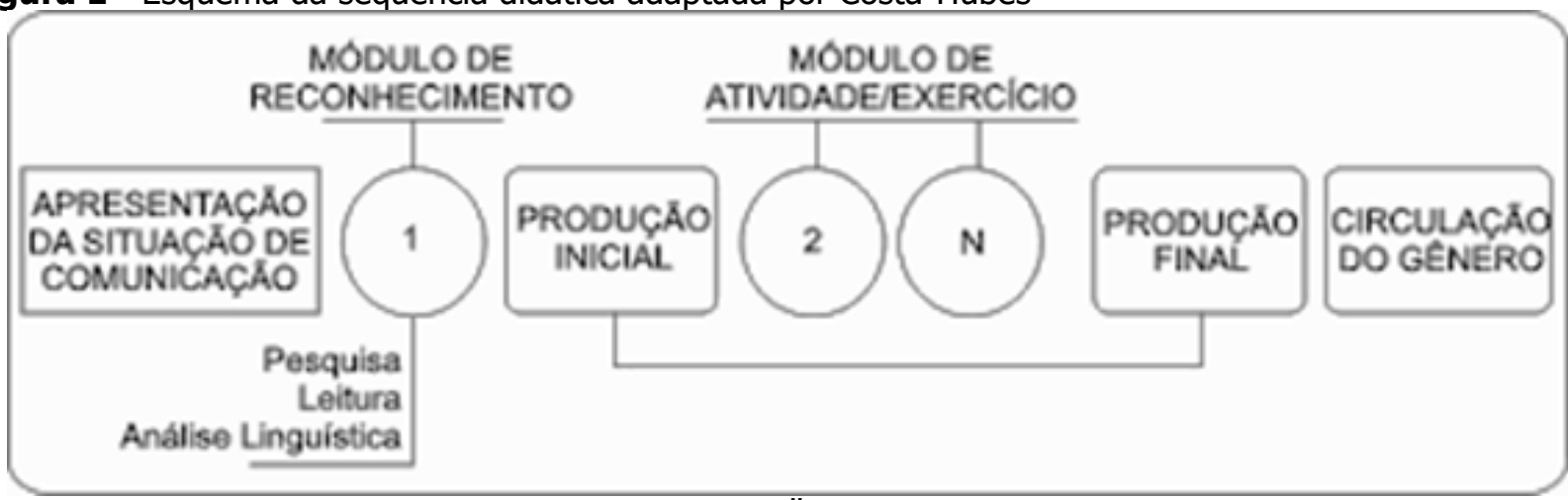

Fonte: Swiderski e Costa-Hübes (2009 apud COSTA-HÜBES; SIMIONI, 2014, p. 26).

Considerando isso, elaborei treze atividades, que são resumidamente dispostas no quadro abaixo, para composição da sequência didática, especificamente para o que pode ser considerado no módulo de reconhecimento do gênero textual crônica.

Quadro 1 - Atividades planejadas para sequência didática

\begin{tabular}{|c|c|c|}
\hline Aspectos metodológicos & Duração & Objetivos \\
\hline $\begin{array}{l}\text { Atividade diagnóstica com o } \\
\text { gênero textual crônica. }\end{array}$ & 2 aulas & $\begin{array}{l}\text { Avaliar os conhecimentos dos alunos na leitura do gênero } \\
\text { textual crônica, bem como sobre a função dos adjetivos no } \\
\text { sentido do texto. Observar aspectos a serem } \\
\text { intervencionados. }\end{array}$ \\
\hline $\begin{array}{l}\text { Aula de apresentação do } \\
\text { estagiário: Resposta à carta. }\end{array}$ & 2 aulas & $\begin{array}{l}\text { Apresentar o professor estagiário, acolher e conhecer os } \\
\text { alunos. Além disso, possibilitar a interação entre a turma e o } \\
\text { estagiário e observar, a partir das respostas à carta, quem } \\
\text { são, o que querem e o que sentem esses alunos. }\end{array}$ \\
\hline $\begin{array}{l}\text { Trilha dos direitos e deveres } \\
\text { em sala de aula. }\end{array}$ & 1 aula & $\begin{array}{l}\text { Conscientizar sobre e estabelecer direitos e deveres de alunos } \\
\text { e de professor estagiário para o bom andamento das aulas no } \\
\text { estágio. }\end{array}$ \\
\hline $\begin{array}{lr}\text { Correção coletiva da } \\
\text { Atividade Diagnóstica. }\end{array}$ & 2 aulas & $\begin{array}{l}\text { Avaliar os conhecimentos dos alunos na leitura do gênero } \\
\text { textual crônica, bem como sobre a função dos adjetivos no } \\
\text { sentido do texto. Observar aspectos a serem } \\
\text { intervencionados. }\end{array}$ \\
\hline $\begin{array}{l}\text { Leitura compartilhada de } \\
\text { crônica e resolução coletiva } \\
\text { de interpretação. }\end{array}$ & 2 aulas & $\begin{array}{l}\text { Compartilhar sentidos e sensações extraídos a partir da } \\
\text { leitura, além de desenvolver estratégias de leitura e observar } \\
\text { alguns aspectos característicos do gênero. }\end{array}$ \\
\hline $\begin{array}{l}\text { Aula expositivo-dialogada } \\
\text { sobre elementos da } \\
\text { narrativa, a partir de crônica } \\
\text { e de material teórico- } \\
\text { didático. }\end{array}$ & 3 aulas & $\begin{array}{l}\text { Aprofundar o conhecimento dos alunos sobre e identificar, no } \\
\text { texto, os elementos da narrativa, bem como desenvolver a } \\
\text { percepção dos movimentos e analisar as contribuições dos } \\
\text { elementos na construção da narrativa. }\end{array}$ \\
\hline $\begin{array}{l}\text { Dinâmica dos emojis e leitura } \\
\text { compartilhada. }\end{array}$ & 2 aulas & $\begin{array}{l}\text { Fortalecer dimensões pessoais, além de compartilhar sentidos } \\
\text { e sensações extraídos a partir da leitura e desenvolver } \\
\text { estratégias de leitura, informar sobre a existência e diferençar } \\
\text { a crônica argumentativa. }\end{array}$ \\
\hline $\begin{array}{l}\text { Leitura compartilhada de } \\
\text { crônica, via texto e curta- } \\
\text { metragem, com atividade de } \\
\text { análise e de escrita. }\end{array}$ & 4 aulas & $\begin{array}{l}\text { Compartilhar sentidos e sensações extraídos a partir da leitura } \\
\text { textual e visual, desenvolver estratégias de leitura, além de } \\
\text { observar diferenças de percepção entre a leitura via texto e } \\
\text { via curta-metragem. Desenvolver estratégias de escrita, bem } \\
\text { como proporcionar momentos de aplicação da criatividade } \\
\text { escritora. }\end{array}$ \\
\hline
\end{tabular}




\begin{tabular}{|c|c|c|}
\hline $\begin{array}{l}\text { Aula expositiva-dialogada } \\
\text { sobre uso de adjetivos e } \\
\text { concordância nominal no } \\
\text { texto, por meio de atividade } \\
\text { de completar lacunas de } \\
\text { crônica com adjetivos. }\end{array}$ & 3 aulas & $\begin{array}{l}\text { Aprofundar o conhecimento e desenvolver a percepção dos } \\
\text { efeitos de sentidos no uso de adjetivos e locuções adjetivas, } \\
\text { bem como observar e analisar a concordância nominal entre } \\
\text { os termos da oração. }\end{array}$ \\
\hline $\begin{array}{l}\text { Leitura compartilhada e } \\
\text { atividade de compreensão de } \\
\text { crônica. }\end{array}$ & 2 aulas & $\begin{array}{l}\text { Compartilhar sentidos e sensações extraídos da leitura da } \\
\text { crônica. Observar e analisar o uso de adjetivos e locuções } \\
\text { adjetivas, bem como seus efeitos de sentidos no texto, e a } \\
\text { concordância nominal entre os termos da oração. }\end{array}$ \\
\hline Atividade diagnóstica final. & 2 aulas & Avaliar o avanço dos alunos a partir dos conteúdos estudados. \\
\hline $\begin{array}{l}\text { Questionário de avaliação do } \\
\text { estágio e cruzadinha sobre } \\
\text { características da crônica e } \\
\text { elementos da narrativa. }\end{array}$ & 1 aula & $\begin{array}{l}\text { Avaliar o período de estágio e o conhecimento dos alunos } \\
\text { acerca das características do gênero e dos elementos da } \\
\text { narrativa. }\end{array}$ \\
\hline Despedida dos alunos. & 2 aulas & Avaliar o período de estágio. \\
\hline
\end{tabular}

Fonte: Produzido pelo autor.

As atividades foram planejadas considerando a perspectiva de leitura como interação autor-textoleitor, considerando que os sujeitos atuam ativamente construindo-se no texto (KOCH; ELIAS, 2006). É uma atividade de construção de sentidos para a compreensão daquilo que é posto, ou pressuposto, envolvendo conhecimentos de mundo, de práticas sociais e linguísticos (ROJO, 2009). Dada essa natureza, considero que estratégias de compreensão, conforme nomenclatura utilizada por Rojo (2009), devem ser desenvolvidas para que a leitura possa ser eficiente. Por essa razão, busquei desenvolver, principalmente, as estratégias de: formulação de hipóteses, ativação de conhecimento de mundo, localização de informações explícitas e implícitas, comparação de informações e inferências.

Além disso, considerando o gênero textual que selecionei para a ação, a crônica narrativa, é constituído predominantemente pela sequência textual narrativa, os seus elementos precisam ser também abordados. Assim, considerei enredo (situação inicial; complicação ou conflito gerador; clímax e desfecho), personagens, narrador, espaço e tempo (ABDALA JUNIOR, 1995; GANCHO, 2002; JUNIOR, 2009) como conteúdos a serem ensinados e aprendidos.

Além do (re)conhecimento das características do gênero, análise linguística também foi realizada a fim de proporcionar a análise de efeitos de sentido do adjetivo e da locução adjetiva na construção da crônica, em concomitância com o estudo da concordância desta classe de palavras com os demais termos da oração. Considero, com base em Costa-Hübes (2010), que a análise linguística se baseia em um trabalho reflexivo que relaciona a organização do texto (em sua situação de produção e interlocução), o gênero textual, o léxico, os mecanismos de textualização e as regras gramaticais necessárias para o uso da língua ali colocado.

Feitas todas essas considerações acerca de como se organizou o planejamento das atividades no processo de ensino-aprendizagem decorrente do estágio, justificando, mesmo que sumariamente, as 
suas devidas escolhas, parto para as reflexões sobre o estar em sala de aula e o praticar as ações pensadas.

\section{REFLEXÕES SOBRE A PRÁTICA DOCENTE}

A expectativa de todo primeiro ato é de medo, insegurança, receio de não agradar. Talvez até termine o espetáculo do ensinar-e-aprender não agradando a alguns, mas há pelo menos uma convicção de que o que podia ser feito assim o foi com toda a dedicação possível. A perfeição é algo quase intangível, e aqui certamente não a toquei. De todo modo, uma coisa fica: o primeiro, tal qual o beijo, foi inesquecível. (COSTA FILHO, 2018 [manuscrito]).

O trecho que inicia esta seção foi retirado de uma crônica, por mim escrita, como forma de agradecimento e despedida para os 41 alunos que, durante as 28 horas/aulas que fizeram parte deste estágio, me permitiram adentrar em seus processos de ensino e aprendizagem de Língua Portuguesa. Esse trecho, certamente, descreve muito bem o que foi sentido durante esse tempo. O medo de errar e de não agradar, de fato, perduraram por aqueles dias, assim como a vontade de realizar tudo com o máximo de dedicação possível. Por isso, essa experiência se tornou inesquecível em minha formação docente e refletir sobre ela, neste momento, é uma forma de compreender um pouco mais sobre a importância da prática e da articulação teoria e prática no processo de formação de professores.

Após a atividade diagnóstica inicial, realizei as devidas apresentações, por meio de uma carta, a qual solicitei que fosse respondida pelos alunos. Essa atividade, que talvez tradicionalmente possa ser vista como inútil, foi de uma riqueza de sentidos, de conhecimento daquele lugar, daqueles alunos.

A partir dela, obtive depoimentos como: "Bom eu sou bem calmo eu como me sento aqui atrás as vezes as reclamações vem ( $(i)$ pra mim e também eu falo muito baixo as vezes eu participo mas os professores não escutam", que me revelou muito mais que uma descrição de um dos alunos, mas um pedido por atenção, de querer participar e, principalmente, querer ser ouvido. De poder sentar em qualquer parte da sala de aula e ser respeitado.

Também pude ler e pensar sobre depoimentos como este: "[...] não gosto muito de escrever, bom, eu tenho uma grande imaginação, mas quando chega no final do texto eu fico com preguiça, e o texto fica uma merda né?", que não representa um aluno que não gosta de escrever, mas, sim, que precisa de um pouco de incentivo, que seus textos não sejam corrigidos visando somente a adequação à norma-culta, que sua criatividade seja estimulada.

Considerar tais respostas, para mim, compreende observar a sala de aula como um ambiente socialmente construído por indivíduos pensantes, que possuem desejos, são e querem ser sujeitos participativos na sociedade, e não somente como um espaço para transmissão de conhecimentos consagrados pela tradição escolar. Obviamente que esses conhecimentos têm, e precisam ter, sua importância para o processo de ensino-aprendizagem, contudo, não é possível se restringir a apenas isso. É preciso possibilitar uma formação ampla e contextualizada, a fim de formar seres humanos emancipados.

Realizar a trilha dos direitos e deveres, por sua vez, além de fugir um pouco do comodismo da aula clássica, possibilitou, novamente, dar voz aos alunos para que eles se colocassem enquanto cidadãos e refletissem sobre os direitos e os deveres deles e do professor em sala de aula. De tal atividade resultou um contrato pedagógico, visando o comprometimento e a colaboração entre mim e os 
alunos, de modo que o respeito entre as partes pudesse prevalecer e as aulas transcorressem da melhor forma possível.

Evidentemente, em alguns momentos cláusulas desse contrato foram desrespeitadas, talvez em decorrência até do grande número de alunos para uma única turma. De todo modo, considero que este instrumento teve o seu valor, principalmente na inclusão dos alunos na cidadania, em concordância, inclusive, com a política que a escola passara a pregar com maior intensidade.

Vale ressaltar, como destaca Scheibel (2006³ apud MAIA, 2009, p. 86), que a escola possui um papel social na "promoção do desenvolvimento do cidadão, no sentido pleno da palavra", afinal, a escola precisa "formar cidadãos conscientes, capazes de compreender e criticar a realidade, atuando na busca da superação das desigualdades e do respeito ao ser humano" (SCHEIBEL, 2006 apud MAIA, 2009, p. 87).

Atividades como essa se voltaram principalmente ao entendimento que o ensino precisa desenvolver dimensões social, interpessoal, pessoal e profissional. Assim, muito mais que habilidades e conhecimentos científico-educacionais e profissionais, o professor deve visionar, em sua prática docente, a plena democracia em todos os âmbitos, a compreensão, tolerância e solidariedade em todas as atividades humanas, e a autonomia na tomada de decisões reflexivas, que proponham posições informadas, críticas, criativas e solidárias (SOUSA, $2002^{4}$ apud MAIA, 2009).

Nas atividades com conteúdos conceituais, focalizei a leitura dos textos selecionados para compartilhamento e construções de sentidos. De maneira geral, organizei o seguinte esquema para realização dessas atividades: associações temáticas $\rightarrow$ leitura silenciosa $\rightarrow$ leitura em voz alta $\rightarrow$ compreensão coletiva do texto $\rightarrow$ atividades escritas individuais. (COSTA FILHO; BAZARIM, 2018). Esse esquema se mostrou proveitoso para os objetivos estabelecidos para as atividades, demonstrando resultados positivos nas interações em sala de aula e na aprendizagem dos alunos.

Obviamente, nem tudo é positivo e nem é meu objetivo parecer que só tive acertos. Enquanto processo, dessabores são comuns e precisam ser considerados para autorreflexão e como pontos de partida para ações futuras - que visem, por sua vez, repensar e ultrapassar esses dessabores. Com isso, percebo que em minha prática talvez tenha faltado um pouco mais de feedback das atividades em sala de aula, de solicitar leitura de respostas, corrigir no quadro, de modo a fazer com que os alunos voltassem à atividade e examinassem-na, consertando possíveis equívocos, possibilitando novas interpretações, já que o exemplo e a repetição também são formas de aprendizagem.

Inclusive, discutindo sobre a inserção da tecnologia no ambiente escolar, Cortella (2014) faz importante distinção entre o que é velho e o que é antigo. Dessa forma, práticas como a realização de exercícios é algo antigo visto seus vários anos de utilização, mas não é algo velho, porque funciona e é necessário. O que pode tornar a ação de usar exercícios ineficiente é centrar a aula apenas nisso,

\footnotetext{
${ }^{3}$ SCHEIBEL, M. F. Função Social do Ensino e suas implicações Didático-Pedagógicas. Caderno Universitário. Canoas: ULBRA, 2006. (No Prelo).

${ }^{4}$ SOUSA, L. P. F. Removendo barreiras à aprendizagem e à participação: ressignificando a prática psicopedagógica nas escolas. www.psicopedagogiaonline.com.br, 2002.
} 
configurando-se como algo velho, já que é necessário que outros mecanismos componham os instrumentos de ensino-aprendizagem.

De mesma forma ocorre com a aula expositiva: é uma ação antiga, mas não é velha, posto que é "possibilidade de eu descrever uma sequência conceitual, fazer com que as pessoas anotem, façam reflexão em torno da temática" (CORTELLA, 2014, p. 62). Já tornar a aula somente expositiva, sendo "aquela que não abra outras portas, utilizando plataformas para continuar a reflexão" (CORTELLA, 2014, p. 62), é velho e, por isso, deve ser evitado.

Portanto, a aula expositiva, com abertura para o diálogo entre estagiário e alunos, também teve espaço em minha prática, principalmente nas ocasiões em que se fizeram necessárias aulas sobre conceitos, como a que tratou dos elementos da narrativa e a da classe dos adjetivos e concordância nominal. Esses momentos foram importantes para o andamento do processo de ensinoaprendizagem, visto a carga teórica que carregavam. Busquei, contudo, sempre munir os alunos com o maior poder de voz possível, com destaque para sempre ter distribuído materiais de apoio impressos, a fim que eles pudessem tirar conclusões próprias.

Quanto ao uso das novas tecnologias, aliás, por mais benéfico e enriquecedor que pareça, muitas vezes atrapalha e impossibilita ou dificulta a execução do planejamento. Nesse estágio, por exemplo, na oportunidade em que a atividade incluía a exibição de um curta-metragem, necessitando, portanto, de Datashow, caixa de som, etc., a primeira tentativa foi frustrante, atrapalhando até mesmo a ordem das demais atividades. Nesta ocasião, os cabos de transmissão da imagem disponíveis na escola não funcionaram. Em segunda tentativa, mesmo de forma improvisada visto a má qualidade de áudio da caixa de som utilizada, consegui realizar parcialmente o que pretendia, realizando as adaptações necessárias à realidade do momento.

Diante do exposto até aqui, o qual acredito ser suficiente para uma visão ampla do que foi realizado em sala de aula durante este estágio, passarei às reflexões finais. Estas concluem, de modo não definitivo, as significâncias do estágio para minha formação docente.

\section{UM OLHAR FINAL}

Neste relato, busquei recuperar as experiências vivenciadas em meu primeiro estágio supervisionado. Nesse caminho, expus, mesmo que sumariamente, todo o processo de preparação, que diz respeito ao planejamento, e de atuação na turma de $9^{\circ}$ ano do Ensino Fundamental de uma Escola Cidadã Integral do município de Campina Grande-PB. No interior das reflexões suscitadas por esse estágio, minha formação docente desenvolveu uma articulação entre os três eixos que considero necessários para as licenciaturas - a teoria aprendida sobre os seus objetos de ensino, os conhecimentos sobre a prática e a própria prática docente.

No papel de professor-estagiário, pude desenvolver e aplicar diversas atividades no campo de atuação da profissão - a escola, especialmente a sala de aula -, em meio a todas as delícias e todos os dessabores que essa experiência pode me proporcionar. Por essa razão, o que apresentei aqui retrata desafios atuais do ser professor, o que pode subsidiar pautas sobre reformulações de currículos a fim de que a formação inicial seja mais condizente com a realidade. De mesma maneira, reitero a importância do estágio supervisionado para as licenciaturas, enquanto espaço de reflexão teoriaprática e de construção da identidade profissional. 


\section{REFERÊNCIAS}

ABDALA JUNIOR, B. Introdução à análise da narrativa. São Paulo: Scipione, 1995.

CANDIDO, A. A vida ao rés-do-chão. In: A crônica: o gênero, sua fixação e suas transformações no Brasil. Campinas: Editora da UNICAMP; Rio de Janeiro: Fundação Casa de Rui Barbosa, 1992.

CORTELLA, M. S. Educação, escola e docência: novos tempos, novas atitudes. São Paulo: Cortez, 2014.

COSTA FILHO, R. B. Lembranças de um estágio, 2018 [manuscrito].

COSTA FILHO, R. B.; BAZARIM, M. As relações entre o enunciado, a produção e a correção de textos. Entrepalavras, Fortaleza, v. 9, n. 3, p. 324-341, set-dez/2019.

COSTA FILHO, R. B.; BAZARIM, M. Planejamento e aplicação de atividades de ensino de Língua Portuguesa no estágio obrigatório dos anos finais do Ensino Fundamental. In: Anais do VI Colóquio Nacional 15 de Outubro. Campina Grande: Revista Letras Raras, 2018.

COSTA-HÜBES, T. C. Uma tentativa de análise linguística de um texto do gênero "relato histórico". Linguagem em (Dis)curso, Palhoça, SC, v. 10, n. 1, p. 181-205, jan./abr. 2010.

COSTA-HÜBES, T. da C.; SIMIONI, C. A. Sequência didática: uma proposta metodológica curricular de trabalho com os gêneros discursivos/textuais. In: BARROS, E. M. de; RIOS-REGISTRO, E. M. (org.). Experiências com sequências didáticas de gêneros textuais. Campinas, SP: Pontes Editora, 2014.

DOLZ, J.; NOVERRAZ, M.; SCHNEUWLY, B. Sequências didáticas para o oral e a escrita: apresentação de um procedimento. In: DOLZ, J; SCHNEUWLY, B e colaboradores. Gêneros orais e escritos na escola. Tradução e organização de Roxane Rojo e Glaís Sales Cordeiro. Campinas-SP: Mercado de Letras, 2004.

GANCHO, C. V. Como analisar narrativas. São Paulo: Ática, 2002.

JUNIOR, A. F. Operadores de leitura da narrativa. In: BONNICI, T.; ZOLIN, L. O. (org.). Teoria literária: abordagens históricas e tendências. 3.ed. Maringá: Eduem, 2009.

KOCH, I. V.; ELIAS, V. M. Ler e compreender: os sentidos do texto. São Paulo: Contexto, 2006.

LIMA, M. S. L. Reflexões sobre o estágio-prática de ensino na formação de professores. Rev. Diálogo Educ., Curitiba, v. 8, n. 23, p. 195-205, jan./abr. 2008.

LUCKESI, C. C. Avaliação da aprendizagem: componente do ato pedagógico. São Paulo: Cortez, 2011a.

LUCKESI, C. C. Planejamento e avaliação na escola: articulação e necessária determinação ideológica. In: Avaliação da aprendizagem escolar: estudos e proposições. 22.ed. São Paulo: Cortez, 2011b.

MAIA, C. M. Escola e professor: função social. In: MAIA, C. M.; SCHEIBEL, M. F.; URBAM, A. C. (org.). Didática: Organização do trabalho pedagógico. Curitiba: IESDE Brasil S.A., 2009.

MENEGOLLA, M.; SANT'ANNA, I. M. Por que planejar? Como planejar? Currículo - área - aula. 22.ed. Petrópolis-RJ: Vozes, 2014. 
PARAÍBA. Medida Provisória no 267 de 07 de fevereiro de 2018. Cria o Programa de Educação Integral, composto por Escolas Cidadãs Integrais - ECI, Escolas Cidadãs Integrais Técnicas - ECIT e Escolas Cidadãs Integrais Socioeducativas - ECIS e institui o Regime de Dedicação Docente Integral - RDDI e dá outras providências. Diário Oficial do Estado da Paraíba, João Pessoa, 09 fev. 2018.

PIMENTA, S. G.; LIMA, M. S. L. Estágio e docência: diferentes concepções. Revista Poíesis, v. 3, n. 3 e 4, p. 5-24, 2005/2006.

ROJO, R. Alfabetismo(s): Desenvolvimento de competências de leitura e escrita. In: Letramentos múltiplos: escola e inclusão social. São Paulo: Parábola Editora, 2009.

SÁ, J. de. A crônica. São Paulo: Editora Ática, 1987. 